\title{
Examining the impacts of behavioral factors on wireless village services among rural community in Malaysia
}

\begin{abstract}
The main attempt of this study is to examine the impacts of behavioural factors on wireless village services among rural community in Malaysia. The study was quantitative in nature where a developed questionnaire was used as the main instrument in collecting the data. Via a multi stage cluster sampling, a total of 400 villagers from four districts in Malaysia have been selected as the respondents for the study. It can be confirmed that all of the behavioural factors studied have a positive and significant relationship with usage of wireless village services. A number of discussion have been highlighted and it is a hope that such discussion can act as a basis for interested parties in constructing concrete strategies to further narrowing the digital gap between the rural and urban communities in Malaysia.
\end{abstract}

Keyword: Rural development; Community development; ICT; Behavioural factors 